Original Article

\title{
Effects of gross motor function and manual function levels on performance-based ADL motor skills of children with spastic cerebral palsy
}

\author{
MYOUNG-OK PARK, MPH, OT ${ }^{1)}$ \\ 1) Department of Occupational Therapy, Division of Health Science, Baekseok University: \\ 76 Munam-ro, Dongnam-gu, Cheonan-si, Chungcheongnam-do, Republic of Korea
}

\begin{abstract}
Purpose] The purpose of this study was to determine effects of Gross Motor Function Classification System and Manual Ability Classification System levels on performance-based motor skills of children with spastic cerebral palsy. [Subjects and Methods] Twenty-three children with cerebral palsy were included. The Assessment of Motor and Process Skills was used to evaluate performance-based motor skills in daily life. Gross motor function was assessed using Gross Motor Function Classification Systems, and manual function was measured using the Manual Ability Classification System. [Results] Motor skills in daily activities were significantly different on Gross Motor Function Classification System level and Manual Ability Classification System level. According to the results of multiple regression analysis, children categorized as Gross Motor Function Classification System level III scored lower in terms of performance based motor skills than Gross Motor Function Classification System level I children. Also, when analyzed with respect to Manual Ability Classification System level, level II was lower than level I, and level III was lower than level II in terms of performance based motor skills. [Conclusion] The results of this study indicate that performance-based motor skills differ among children categorized based on Gross Motor Function Classification System and Manual Ability Classification System levels of cerebral palsy.

Key words: Performance based motor skill, Gross Motor Function Classification System, Manual Ability Classification System
\end{abstract}

(This article was submitted Jul. 28, 2016, and was accepted Nov. 14, 2016)

\section{INTRODUCTION}

Cerebral palsy is a non-progressive disease resulting from brain injury. The disease can impair motor skills ${ }^{1)}$. The major problem of children with cerebral palsy is an inability to use movement control for balance as well as an inability to use the hands for reaching and manipulation in daily activities ${ }^{2}$. In daily life activities, children's motor skills also affect their physical capability and environmental context ${ }^{3)}$. Therefore, children's physical capabilities must be evaluated in a real occupational environment.

Several well-established classification systems are used to characterize the functional abilities of children with cerebral palsy as they participate in their daily activities. The classification systems are divided in two types: the Gross Motor Function Classification System (GMFCS) and the Manual Ability Classification System (MACS) . GMFCS scores range from Level 1, which includes children with no disability and community mobility, to Level 5, which includes children who are totally dependent on assistance for mobility ${ }^{4}$. The MACS provides information for classifying the manual abilities of children with cerebral palsy, whether they are using their hands for manipulation or not ${ }^{4)}$. Both classification systems are used to evaluate children's functional status in daily routine activities.

The skill of performance in daily routine activities is very important in evaluating children with cerebral palsy. In general,

Corresponding author. Myoung-Ok Park (E-mail: parkmo@bu.ac.kr)

(C2017 The Society of Physical Therapy Science. Published by IPEC Inc.

This is an open-access article distributed under the terms of the Creative Commons Attribution Non-Commercial No Derivatives (by-nc-nd) License $<$ http://creativecommons.org/licenses/by-nc-nd/4.0/>. 
Table 1. General characteristics of all children $(\mathrm{N}=23)$

\begin{tabular}{|c|c|c|c|}
\hline & & Mean \pm SD [Range] & Frequency (\%) \\
\hline Age (years) & & $9.04 \pm 1.02[8-11]$ & \\
\hline \multirow{2}{*}{ Gender } & Boys & & $14(60.9)$ \\
\hline & Girls & & $9(39.1)$ \\
\hline \multirow{5}{*}{ GMFC Level } & I & & $2(8.7)$ \\
\hline & II & & $7(30.4)$ \\
\hline & III & & $14(60.9)$ \\
\hline & IV & & 0 \\
\hline & V & & 0 \\
\hline \multirow{5}{*}{ MACS Level } & I & & $2(17.4)$ \\
\hline & II & & $13(56.5)$ \\
\hline & III & & $6(26.1)$ \\
\hline & IV & & 0 \\
\hline & $\mathrm{V}$ & & 0 \\
\hline
\end{tabular}

performance skills can be evaluated using real tasks in the environment. Children's performance skill in daily activities should reflect real functions while they perform real activities such as dressing and hygiene, which are influenced by environmental, personal and contextual factors ${ }^{5}$. Therefore, real performance-based evaluation is important in correctly assessing a child's degree of functional skill. Nowadays, for performance-based evaluation, the Assessment of Motor and Process Skill (AMPS) or school AMPS is used. The AMPS is used to evaluate performance skills when children and adults perform daily tasks. It comprises two main areas: ADL motor skill and ADL process skill ${ }^{6)}$.

According to Fisher, the AMPS ADL motor skills refer to observable actions of performance used to move oneself or task objects, such as reaching, alignment and bending. Process skills refer to observable actions, such as the ability to logically organize actions in time and space and the appropriate use of task tools. "Motor skills" refer in particular to the gross and fine motor capability of an individual when performing a daily occupation ${ }^{7}$. Various studies have reported on the strengths of the performance-based evaluation. To date, there has been little published evidence regarding the utility of performance-based evaluations in assessing functional ability in children with cerebral palsy.

The aim of this study was to investigate the predictive utility of GMFCS and MACS levels with respect to the performancebased ADL motor skills of children with cerebral palsy.

\section{SUBJECTS AND METHODS}

This study included 23 children with cerebral palsy, who attended a pediatric rehabilitation hospital in Seoul. All children and their caregivers were informed about the purpose of this study in accordance with the ethical principle of the Declaration of Helsinki (1975, revised 1983). The study subjects were children with cerebral palsy aged 7-12 years old, with mild to moderate spastic cerebral palsy, who had been categorized as GMFCS and MACS Levels I-III. Children with mixed diagnoses (e.g., severe visual and auditory problems or intellectual disability) were excluded.

The GMFCS and MACS were used to assess the functional capabilities of children with cerebral palsy. Notably, the GMFCS uses five levels to classify those who are being evaluated. For example, Level I patients walk without limitation. Children at this level can be independent in terms of mobility ${ }^{3)}$. Level IV patients exhibit self-mobility with limitations. Level V patients exhibit self-mobility with severe limitations ${ }^{3)}$.

The MACS uses five levels to classify those who are being evaluated. For example, patients classified as Level I handle objects easily and successfully, while those classified as Level IV handle a limited selection of easily managed objects in adapted situations. Those classified as Level V do not handle objects ${ }^{4}$.

The AMPS was used to evaluate each child's level of performance skill. For the AMPS assessment, participants were asked to complete functional tasks such as dressing, donning shoes and preparing cereal and milk. Each child chose two tasks from among these options. Only ADL motor skills assessed using the AMPS were analyzed statistically. Notably, motor skills represent the gross and fine motor capability of a person, while process skill is more related to cognitive and mental process capability. Descriptive statistics were used to analyze the demographic characteristics of the children who participated in the study (Table 1). One-way ANOVA and the post-hoc test in combination with Scheffe's method were used to determine the mean difference in ADL motor skills among GMFCS and MACS levels. Multiple regression analysis was used to determine the relationships among ADL motor skill, GMFCS level and MACS level. Each GMFCS and MACS level was analyzed using dummy variables. SPSS win version 20.0 was used for statistical analysis. The level of statistical significance was set at 0.05 . 
Table 2. Mean difference of ADL-motor skill among GMFC and MACS levels $(\mathrm{N}=23)$

\begin{tabular}{lccccc}
\hline & Level I & Level II & Level III & Average & Post-hoc \\
\hline ADL-motor skill among GMFCS level* & $117.50 \pm 3.53$ & $99.85 \pm 11.33$ & $78.50 \pm 16.63$ & $88.39 \pm 19.50$ & $\mathrm{a}=\mathrm{b}, \mathrm{a}>\mathrm{c}, \mathrm{b}>\mathrm{c}$ \\
ADL-motor skill among MACS level** & $108.75 \pm 10.30$ & $87.76 \pm 18.17$ & $76.16 \pm 17.47$ & $88.39 \pm 19.50$ & $\mathrm{a}=\mathrm{b}, \mathrm{a}>\mathrm{c}, \mathrm{b}=\mathrm{c}$ \\
\hline
\end{tabular}

*Significant difference at 0.002 level, **Significant difference at 0.026 level

$\mathrm{a}=$ level I, b=level II, c=level III

Table 3. Multiple regression model to predict ADL-motor skill using GMFCS level (N=23)

\begin{tabular}{llccc}
\hline GMFCS level & $\mathrm{B}$ & $\mathrm{SE}$ & $\mathrm{t}$ & $\mathrm{R}^{2}$ \\
\hline Constant & $117.50^{*}$ & 10.46 & 11.25 & \\
Level II & -17.64 & 11.86 & -1.48 & 0.476 \\
Level III & $-39.00^{* *}$ & 11.19 & -3.48 & \\
\hline
\end{tabular}

*Significant level at $<0.0001, * *$ Significant level at 0.002

$\mathrm{B}$ : coefficient of regression, SE: standard error, t: calculated value, $\mathrm{R}^{2}$ : coefficient of determination

Table 4. Multiple regression model to predict ADL-motor skill using MACS level $(\mathrm{N}=23)$

\begin{tabular}{llccc}
\hline GMFCS level & \multicolumn{1}{c}{$\mathrm{B}$} & $\mathrm{SE}$ & $\mathrm{t}$ & $\mathrm{R}^{2}$ \\
\hline Constant & $108.75^{*}$ & 8.52 & 12.76 & \\
Level II & $-20.98^{* *}$ & 9.74 & -2.15 & 0.306 \\
Level III & $-32.58^{* * *}$ & 11.00 & -2.96 & \\
\hline
\end{tabular}

*Significant level at $<0.0001, * *$ Significant level at $0.044, * * *$ Significant level at 0.008 $\mathrm{B}$ : coefficient of regression, SE: standard error, t: calculated value, $\mathrm{R}^{2}$ : coefficient of determination

\section{RESULTS}

ADL motor skills differed significantly among GMFCS $(p=0.002)$ and MACS levels $(p=0.026)$. A post-hoc test revealed a significant difference between GMFCS Levels I and III $(\mathrm{p}=0.009)$ as well as between Levels II and III ( $\mathrm{p}=0.019)$. There was no significant mean difference in ADL motor skill between GMFCS Levels I and II. There were also significant mean differences in ADL motor skill between MACS Levels I and III ( $\mathrm{p}=0.026)$ (Table 2). The results of multiple regression models were as follows. In comparison to GMFCS Level I, Level III ADL motor skills were 39.0 points lower $(p=0.002)$. This regression model's explanation power was 47.6\% (Table 3). In comparison to MACS Level I, Level II ADL motor skills were 20.98 points lower $(\mathrm{p}<0.0001)$; Level III ADL motor skills were 32.58 points lower $(\mathrm{p}=0.044)$. This regression model's explanation power was $30.6 \%$ (Table 4 ).

\section{DISCUSSION}

Children with cerebral palsy exhibit poor participation in daily activities due to motor problems such as abnormal postural tone and poor body control ${ }^{8)}$. This study demonstrated the clinical utility of a performance-based assessment based on the AMPS motor skill test in predicting the gross and manual functions of children with cerebral palsy. First, ADL motor skills in children differed significantly among GMFCS and MACS levels. This result was reported previously ${ }^{9}$. According to James et al., AMPS motor skills are related to hand function in unilateral cerebral palsy ${ }^{9}$. Another previous study demonstrated correlations among GMFCS, MACS and Wee FIM scores. Gunnel et al. showed a significant correlation among GMFCS scores, MACS scores and the self-care, mobility and locomotion scores of the wee FIM ${ }^{10)}$. This outcome was similar to that presented here. Moreover, in this study, multiple regression showed that the ADL motor skills of children with GMFCS Level III scored lower than those of children categorized as GMFCS Level I. Also, in comparison to children classified as MACS level I, children labeled as MACS Level II and III had inferior ADL motor skills. Thus, ADL motor skills differ significantly among GMFCS Level III, MACS Level II and MACS Level III among children with cerebral palsy. These results suggest that ADL motor skills can be used to predict GMFCS or MACS level in children with cerebral palsy.

This study has some limitations. Only spastic-type cerebral palsy patients classified as GMFCS or MACS Levels I-III participated. Thus this study could not characterize the relationship between ADL motor skills and other GMFCS or MACS 
levels. Future research is necessary to involve children with various type of cerebral palsy such as hemiplegia, diplegia and ataxic type. Furthermore, future research need to investigating ADL motor skills that correlation with other GMFCS or MACS levels.

\section{ACKNOWLEDGEMENT}

This study was supported by the Baekseok University research fund.

\section{REFERENCES}

1) Bedford S, McKinaly I: Elements of pediatric physiotherapy, disorders of the central nervous system. Pamela ME (ed.). Churchill Living Stone, 1993, pp $113-130$.

2) Eliasson AC: Improving the use of hands in daily activities: aspects of the treatment of children with cerebral palsy. Phys Occup Ther Pediatr, 2005, 25: 37-60. [Medline]

3) Ko JY, Woo JH, Her JK: The reliability and concurrent validity of the GMFCS for children with cerebral palsy. J Phys Ther Sci, 2011, 23: 255-258. [CrossRef]

4) Eliasson AC, Krumlinde-Sundholm L, Rösblad B, et al.: The Manual Ability Classification System (MACS) for children with cerebral palsy: scale development and evidence of validity and reliability. Dev Med Child Neurol, 2006, 48: 549-554. [Medline] [CrossRef]

5) James S, Ziviani J, Boyd R: A systematic review of activities of daily living measures for children and adolescents with cerebral palsy. Dev Med Child Neurol, 2014, 56: 233-244. [Medline] [CrossRef]

6) Van Zelst BR, Miller MD, Russo R, et al.: Activities of daily living in children with hemiplegic cerebral palsy: a cross-sectional evaluation using the Assessment of Motor and Process Skills. Dev Med Child Neurol, 2006, 48: 723-727. [Medline] [CrossRef]

7) Fisher AG: The assessment of IADL motor skills: an application of many-faceted Rasch analysis. Am J Occup Ther, 1993, 47: 319-329. [Medline] [CrossRef]

8) Campbell SK: Efficacy of physical therapy in improving postural control in cerebral palsy. Pediatr Phys Ther, 1990, 2: 135-140. [CrossRef]

9) James S, Ziviani J, Ware RS, et al.: Relationships between activities of daily living, upper limb function, and visual perception in children and adolescents with unilateral cerebral palsy. Dev Med Child Neurol, 2015, 57: 852-857. [Medline] [CrossRef]

10) Gunel MK, Mutlu A, Tarsuslu T, et al.: Relationship among the Manual Ability Classification System (MACS), the Gross Motor Function Classification System (GMFCS), and the functional status (WeeFIM) in children with spastic cerebral palsy. Eur J Pediatr, 2009, 168: 477-485. [Medline] [CrossRef] 